\title{
Development of a Condition Based Maintenance Architecture for Optimal Maintainability of Mine Excavators
}

\author{
*Prakash Kumar **Srivastava, R.K. \\ *Assistant Professor, Production Engineering Department, **Professor \& Head, Production Engineering \\ Department, B. I. T. Sindri, Dhanbad-828123
}

\begin{abstract}
Today's competitive environment requires that industries succeed in sustaining full production capabilities, while minimizing capital investment. From a maintenance perspective, this means maximizing equipment reliability (i.e., achieving maximum uptime), while extending the plants life. This proactive approach needs a Total Planned Quality Maintenance (TPQM) program, the systemizing of all (i.e., preventive, predictive, and planned) maintenance, plus the control by condition based maintenance architecture. As the global marketplace becomes more competitive, such advantages are necessary in order to maintain the large capital mining machineries economic health. The strategic dimensions of maintenance management form the basis for wise decision-making, which can be performed by organizational design, maintenance methodology, adequate support systems, corporate culture and effective maintenance.

Although, extensive data base and knowledge pool are available regarding maintenance, its methodology and concerned feedback mechanism, but no suitable or custom built maintenance strategy is yet available for specific mining machinery including mining excavators. Research and Development of a custom built maintenance System is the need of the day because of large capital, productivity and risk involved with the mine excavators in a high capital intensive industrial scenario with acute sensitivity in the performance of such machines.

This paper discusses a condition based maintenance architecture program for Optimal Maintainability of mine excavators. The Optimal Maintainability Program (OPM) includes various functional analysis of excavators and its component and various sub-components.
\end{abstract}

\section{Introduction}

Open cast mining is the most common method of mine production in the world. In open cast mining, the required production is provided by various equipment groups, having different types and capacities. Mine excavator is one of them. It is a mega sized equipment, which requires a great investment. So, strategic maintenance is necessary and the whole maintenance methodology must be carefully analyzed for optimum maintenance of this equipment.

This paper discusses a maintenance strategy system for Optimal Maintainability Program (OMP) of mine excavators. The OMP includes various functional analysis of excavators and its components such that the maintenance cost is minimized and technical constraints ( such as engine, hydraulic and transmission system, break system, electrical and safety system, suspension and track) are efficiently monitored and maintained. These technical constraints depends upon many factors such as a) Geotechnical parameters, b) Geological parameters, c) Mine parameters, d) Production rate, e) Equipment specification and f) Dig ability assessment etc.

Based on the above factors maintenance plans are prepared for predicting/accessing the equipment / component failures. For component failure detection, which is performed continuously, we can use data base similar to that monitored by protective devices to detect abnormalities in behavior, FMEC analysis, FMEA worksheet, Condition based monitoring system. Based on these analysis an Expert System has been developed for optimal maintainability of mining excavators.

\section{A. Primary Function}

\section{Optimal Maintenance Process Function}

1. Database For Monitoring And Control- Databases are generated regarding excavator database and its various forms, production capacity, equipment specification, production rate etc. Data is continuously and periodically monitored and selected data is stored in the databases and referred as historical maintenance database. Three categories of historical data is stored in the data base. The first category represents all systems data measured during the past 20 periodic monitoring sessions. Second category - for each periodic monitoring sessions in which a deteriorating components is detected is stored in the database. The third and the last category represents all system data measured during each condition monitoring sessions in which a component failures are detected. 


\section{B. Secondary Function}

1. FMECA - The FMECA takes into account the following six parameters / (Weight of Parameters): S (Safety) (1.5), IP (Machine importance) (03), MC (Maintenance cost) (02), FF (Failure frequency) (1.5), DL (Downtime length (01) and OC (Operating conditions) (01).

\section{Criticality Index :}

C.I $=(\mathrm{S} x$ wt. value of S)+(IP $\mathrm{x}$ wt. value of IP $)+(\mathrm{MC} \times$ wt. value of MC)+(DL $\mathrm{x}$ wt. value of DL)+(OC x wt. value of OC) ,Scale for S, IP, MC, FF, DL and OC: 81-100...Very High, 61-80...High, 41$60 \ldots$ Normal, $21-40 \ldots$ Low, $0-20 .$. Very Low. Weight values assigned to the relevant parameters considered in rule based system and the maintenance policy must be based on these rules for different excavator's components.

\begin{tabular}{|l|l|l|}
\hline Criticality Index & Maintenance policy & Mine Excavator components \\
\hline$>395$ & Predictive & $\begin{array}{l}\text { Engine, Hydraulic and transmission } \\
\text { system }\end{array}$ \\
\hline $280-394$ & Preventive & Break and Electrical system \\
\hline$<280$ & Corrective & Suspension, track and tyre. \\
\hline
\end{tabular}

\section{FMEA (Case Study)}

If we take the case of five different types of mining (hydraulic) excavators, however, all are very similar, if not identical. The primary research involved in the identification of the different components/ subcomponents and corresponding failure modes for the excavators: example- electric motor, bearing system , hydraulic system etc. These systems have some equipments associated with the sub-system. Through extensive research, relevant maintenance data were collected of all the possible failure modes. Such data/information were recorded on reliability centered maintenance analysis or, FMEA (Failure Mode and Effect Analysis) work sheets (Table-I). We can take the numeric parameters like : Severity (S),Occurrence $(\mathrm{O})$, Detection $(\mathrm{D})$ and risk priority number ${ }^{\circledR}$, given for each failure mode and applied to the five different types of Hydraulic Excavators (Table- II).

\section{System and Equipment considered (Table I \& II)}

System considered such as Electric motors, Bearing system and Hydraulic system.

Equipment considered for analysis such as Coil stator Temperature, Core stator Temperature, Cold air Heat exchanger, Hot air Temperature, Coil excitation Temperature for Electric motors.

Metal Guide Temperature, Oil Guide Temperature, Oil tank level ,Oil tank pressure, Oil tank Temperature etc for Bearing system.

Water flow, water pressure and water temperature etc for Hydraulic system.

\section{Tertiary Function}

1. Condition-Based Maintenance Architecture

Many components of excavator (Mechanical and Hydraulic system) do not have a clear and visible wear-out devices and are thus not applicable for scheduled overhauls. Condition based maintenance (CBM), with condition monitoring are introduced as one solution for some of these potential failures. CBM is defined as: "Preventive maintenance based on performance and/or parameter monitoring and the subsequent actions". Condition monitoring can be performed using different levels of technology. The purpose of condition monitoring of a machine is to collect condition data to make it possible to detect incipient failure, so that maintenance tasks can be planned at a proper time.

CBM is applied in order to give input to decide maintenance actions dynamically. CBM is performed to serve two purposes: first is to determine if a problem exists in the monitored excavator, how serious it is, an incipient failure, so that maintenance tasks can be planned at a proper time, and second is to detect and identify specific degrading components in the excavator.

\section{CBM architecture contains seven layers:}

Data Acquisition - Information/data collected from sensor, transmitter or another sources. With this signal the system capture the dynamic effect caused by the incipient failure of excavator.

Signal processing - The purpose of signal processing in diagnostic applications and CBM is:

A) remove distortions and restore the signal to its original shape, B) remove sensor data that is not relevant for diagnostics, and $\mathbf{C}$ ) transform the signal to make relevant features more explicit.

Condition Monitor - This layer compares on-line, real time data with its expected values. The condition monitor should also be able to generate alerts in open cast mines based on preset operational limits. 
Health Assessment - The primary focus of the health assessment layer is to prescribe if the health of the monitored excavator has degraded. The health assessment layer should be able to generate diagnostic records and propose fault possibilities in the excavator.

Prognostics - This layer require logistic data from the previous layers. The primary focus of the prognostic module is to calculate the future health of an excavator.

Decision Support - The previous layer should be integrated into a decision support for the best possible solution. The primary function of decision support is to provide recommended maintenance actions for different types of excavators.

Presentation - The presentation layer receives data from the previous layers which contains health assessment, prognostic and decision. The presentation module could be built into a user interface.

Table I: Fmea Work Sheet

\begin{tabular}{|c|c|c|c|c|c|}
\hline Component & function & failure mode & Effects & Cause & Control \\
\hline \multirow{4}{*}{ 1. Pumps } & \multirow{4}{*}{ Oil Pump } & $\begin{array}{l}\text { 1.1. Low } \\
\text { Pressure } \\
\text { Operation } \\
(<2 \text { bar })\end{array}$ & $\begin{array}{l}\text {-Turn off the priority pump } \\
\text { and turn on the altemative } \\
\text { pumps in low pressure. } \\
\text { - Lubrication and cooling } \\
\text { Failure. }\end{array}$ & $\begin{array}{l}\text { Oil leaks by the } \\
\text { mechanical seal. } \\
\text {-Coupling damage } \\
\text { - Corrosion by } \\
\text { cavitations oil } \\
\text { - Cavitations by } \\
\text { Presence air in oil. }\end{array}$ & $\begin{array}{l}\text { Oil pressure } \\
\text { transmitter } \\
\text { in the pump } \\
\text { out. }\end{array}$ \\
\hline & & $\begin{array}{l}\text { 1.2. High } \\
\text { Pressure }\end{array}$ & \multirow{3}{*}{$\begin{array}{l}\text {-Turn off the priority pump } \\
\text { and turn on the altemative } \\
\text { pumps in high pressure. } \\
\text { - pump failure risk } \\
\text { - Crack tubes and leaks } \\
\text { - Lubrication and cooling } \\
\text { failure. } \\
\text { - pump failure risk }\end{array}$} & \multirow[b]{2}{*}{-Incorrect adjustment } & $\begin{array}{l}\text { Oil pressure } \\
\text { transmitter }\end{array}$ \\
\hline & & $\begin{array}{l}\text { Operation } \\
\text { ( }<6 \text { bar })\end{array}$ & & & $\begin{array}{l}t \text { in the pump } \\
\text { out. }\end{array}$ \\
\hline & & $\begin{array}{l}1.3 \text { Abnormal } \\
\text { Sound }\end{array}$ & & $\begin{array}{c}\text { - Bearing wear } \\
\text {-Bad bearing lubrication }\end{array}$ & $\begin{array}{l}\text { Sound } \\
\text { inspection }\end{array}$ \\
\hline \multirow{3}{*}{$\begin{array}{l}\text { 1. Heat } \\
\text { Exchanger }\end{array}$} & \multirow{3}{*}{$\begin{array}{l}\text { To cool } \\
\text { the oil }\end{array}$} & $\begin{array}{l}\text { 2.1Insufficient. } \\
\text { Cool of oil }\end{array}$ & $\begin{array}{l}\text {-Lost oil's physic-chemist } \\
\text { characteristics } \\
\text { - cooling failure. }\end{array}$ & \multicolumn{2}{|r|}{$\begin{array}{r}\text { Temperature } \\
\text { transmitter }\end{array}$} \\
\hline & & 2.2. Oil leaks & $\begin{array}{l}\text {-Oil contamination risk } \\
\text {-Lost oil's physic-chemist } \\
\text { Characteristics } \\
\text { - cooling failure }\end{array}$ & $\begin{array}{l}\text {-Stud bolt wear } \\
\text {-Plate pack } \\
\text { connections slack }\end{array}$ & $\begin{array}{l}\text { Oil flow } \\
\text { transmitter }\end{array}$ \\
\hline & & 2.3 Water leaks & - cooling failure & $\begin{array}{c}\text { - Slack tubes } \\
\text { Connections of water }\end{array}$ & $\begin{array}{l}\text { Water flow } \\
\text { Transmitter }\end{array}$ \\
\hline
\end{tabular}

Table Ii: Critical Failure Analysis Based On Fmea Work Sheet

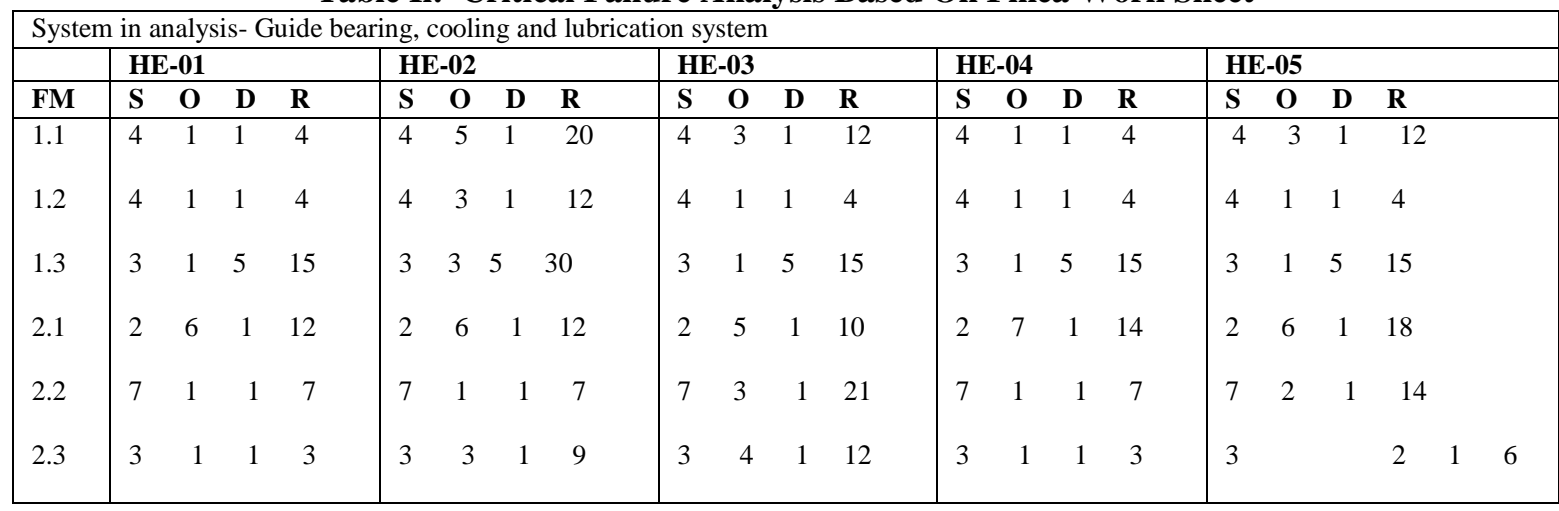

\section{Development Of An Expert System}

Based on FMEA, FMECA work sheet and Condition Based Maintenance (CBM) architecture an expert system has developed for optimal maintainability.

Early recognition of failure modes represents the most efficient way to reduce the probability of excavator components failure. However, a major obstacle to the assessment of this failure modes in mining is the inability to provide mining maintenance practitioners with the necessary knowledge concerning preventive maintenance analysis. One possible solution to overcome this obstacle is the use of computer assisted systems such as ESs. ESs are computer programs that use numerical or non-numerical information to solve problems. 
For the development of this ES, the standardization of a failure code classification, the list of the equipments in the mining and the creation of decision codes were first performed. Through the failure history analysis, maintenance manuals, FMEA, FMECA,CBM and the expert knowledge, the rule base has been constructed using CLIPS (C Language Integrated Production System) programming language. The goal of the system is provide to the non-experts in mining maintenance with a list of possible failure modes and the decisions to be adopted.

A CBM system was developed to incorporate the knowledge contained in the equipment evaluation documents, mining machinery failure modes and knowledge from experts in maintenance. This knowledge encapsulation process was carried out systematically to consider all the different key factors in the analysis accordingly. The knowledge obtained was then organized and analyzed. From this analysis, the system architecture was defined, and the initial set of inference rules was constructed.

\section{Typical example of Expert system for engine maintenance of an excavator} Case I : Engine Maintenance :

IF oil viscosity is low, IF mileage schedule is completed,

IF number of days has expired

IF filter paper condition has deteriorated

THEN change the oil filter, change the oil

IF life cycle of component has not expired

IF breakdown has not occurred in component

IF Heavy production schedule is not meet

IF Impaired functioning of component takes place

IF weather component likely to fail

THEN go for scheduled maintenance ELSE

REPLACE THE COMPONENTS WITH EXPIRED LIFE CYCLE

IF Impaired functioning of components.

IF Components not meeting the required performance standard

IF components lifecycle completion is nearer

IF condition monitoring for equipments of performance not satisfactory

IF Vibration level, noise level, temperature level is beyond acceptable limit

THEN

GO FOR MAJOR OVERHAULING.

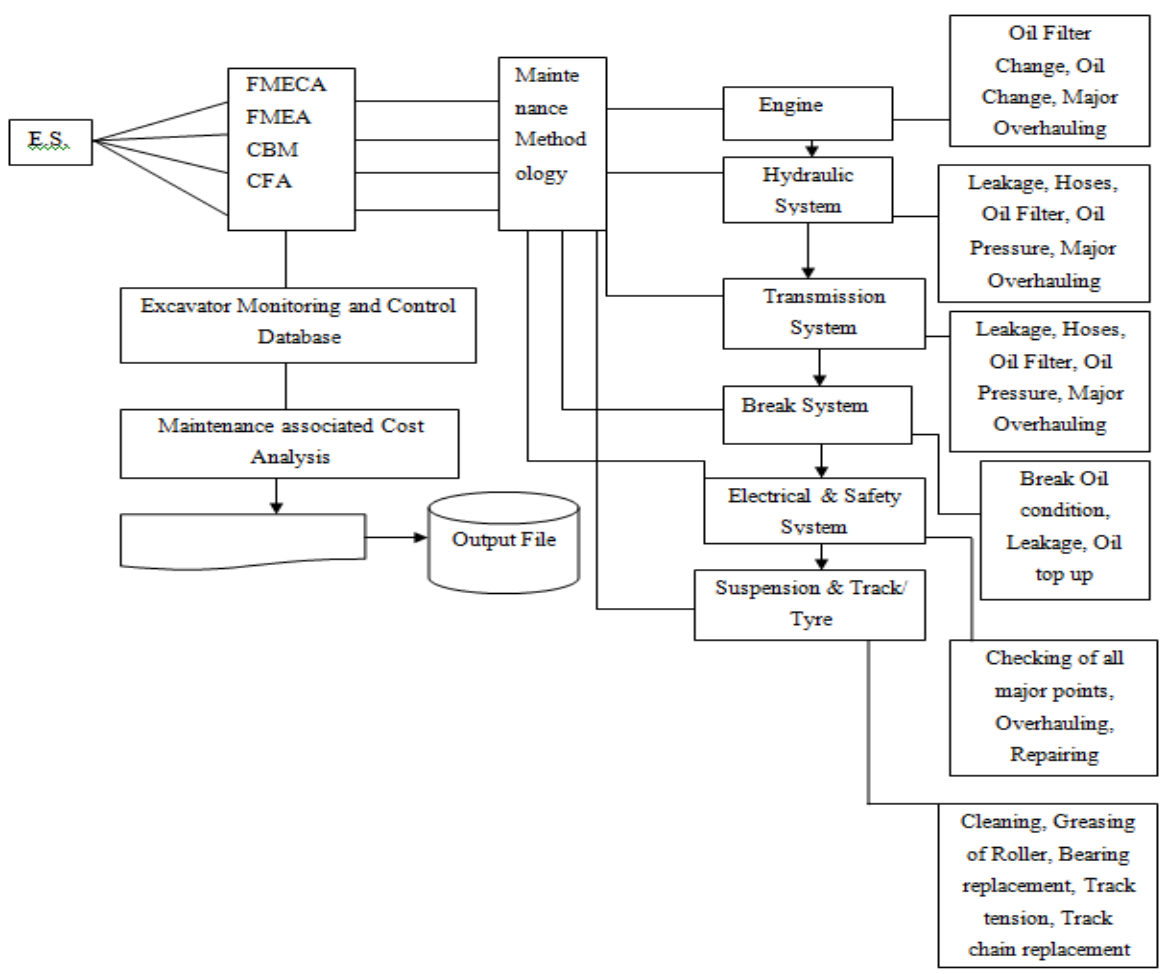




\section{Conclusion}

An optimal system for maintenance of mining excavators (Hydraulic,Bucket and Wheel) has been developed. These mining excavators are increasingly being used in open cast mining. The monitoring and control system has equipment database obtained from manufacturers and mine specific data are entered into the system.

The paper has presented the framework for a new optimal maintenance methodology for mine excavator's components failure detection and system related failures and accordingly databases are formed by the FMEA, FMECA and CBM models which predict fault or deterioration in excavator components. The main aim is to select the optimum maintenance methodology to reduce the maintenance related cost as well as to reduce the unit production cost in mining.

\section{References}

[1] Adhammar Et.al, Preventive Management/Essential care Condition monitoring,

[2] D.W.Rolston, Principles of Artificial Intelligence and Expert Systems Development, McGraw-Hill, 1988

[3] Fytas. K. Collins, J.L.Flament, Potential applications of knowledge-based systems in mining. CIM Bulletin,Vol.81, 1988, PP $38-43$.

[4] Gurtsbach I.B, Modele of Preventive Maintenance.

[5] Jim Parentzas, A Wab- Based controlled By a Hybrid expert System.

[6] Jardine AKS, Maintenance, Replacement \&Reliability,Pitman publication

[7] J.H.Williams, A. Davies and P.R.Drake, Condition -Based Maintenance and Machine Diagnostics, Chapman \& Hall, 1994

[8] Morrow,L.C., Maintenance Engg. Hand Book ,Mc Graw Hill

[9] M.H. Lee, Knowledge Factory,Artif. Intell Engg.

[10] M.Maquire, Predictive Maintenance : What Does It Do? Electrical World, June 1992, PP 325-336

[11] Prakash Kumar,Srivastava.R.K, An expert System for predictive maintenance of mining excavators and its various forms in open cast mining. IEEE Xplore -IEEE Conference Publication, Print ISBN: 978-1-4577-0694-3, Pg.658-661,Publication Year 2012 .

[12] R.Keith ,Lindley R.Higgins, Darrin J. Wikoll, Maintenance Engg. Hand Book $7^{\text {th }}$ edMc Graw Hill. 